\title{
A virtual classroom can elicit teachers' speech characteristics: Evidence from acoustic measurements during in vivo and in virtuo lessons, compared to a free speech control situation
}

Angélique Remacle, $\mathrm{PhD}^{1,2,3}$, Stéphane Bouchard, $\mathrm{PhD}^{4,5}$, Anne-Marie Etienne, $\mathrm{PhD}^{2}$, MarieChristine Rivard ${ }^{4}$, Dominique Morsomme, $\mathrm{PhD}^{2}$

${ }^{1}$ Fund for Scientific Research - F.R.S.-FNRS, Brussels, Belgium

${ }^{2}$ Département de Logopédie, Faculté de Psychologie, Logopédie et Sciences de l'Éducation, Université de Liège, Liège, Belgium

${ }^{3}$ Faculté des Sciences Psychologiques et de l'Éducation, Université Libre de Bruxelles, Brussels, Belgium

${ }^{4}$ Département de Psychoéducation et de psychologie, Université du Québec en Outaouais, Gatineau, Canada

${ }^{5}$ Centre de Santé et de Services Sociaux de l'Outaouais, Gatineau, Canada

Corresponding author: Dr. Angélique Remacle

Mailing address: $\quad$ Université de Liège Faculté de Psychologie, Logopédie et Sciences de l'Education Département de Logopédie Unité Logopédie de la Voix Rue de l'Aunaie, 30 (B38) 4000 Liège (Belgium)

Phone number: $\quad+3243663602$

Email address: angelique.remacle@uliege.be 
Teachers' speech in a virtual classroom

\title{
A virtual classroom can elicit teachers' speech characteristics: \\ Evidence from acoustic measurements during in vivo and in virtuo lessons, compared to a free speech control situation
}

\begin{abstract}
To achieve pedagogic goals and deal with environmental constraints such as noise when lecturing, teachers adapt their speech production in terms of frequency, intensity, and temporal aspects. The mastery of appropriate vocal skills is key to teachers' speech intelligibility, health, and educational effectiveness. This project tests the relevance of virtual reality (VR) for training teachers' vocal skills by simulating a lesson in a realistic VR environment characterized by adjustable constraints such as background noise and fidgety children. The VR environment depicts an elementary school classroom with 16 pupils aged 9 to 12 years old animated with typical childlike actions.

To validate this virtual classroom in terms of speech characteristics, we conducted acoustic analyses on the speech productions of 30 female teachers in three conditions: (1) giving a free speech while facing the experimenter (control), (2) teaching in their usual classroom (in vivo), and (3) teaching the same lesson in a virtual classroom (in virtuo). The background noise in the VR setting was adjusted for each talker so it was similar to the level measured in vivo. Repeated measures ANOVAs showed that teachers significantly increased their voice frequency, intensity, and intonation, and made longer pauses while speaking in vivo and in virtuo, compared to the control condition $(\mathrm{p}<.001)$. These voice and speech adaptations (partly related to background noise), the strong feeling of presence and the lack of side effects suggest that the virtual classroom may facilitate voice training and rehabilitation for teachers.
\end{abstract}


Teachers' speech in a virtual classroom

\section{Introduction}

In elementary school, information is predominantly presented orally to children. Teachers use their voices to pursue different goals: (1) pedagogic: the challenge of catching the pupils' attention, and helping them understand and retain a message (Manfredi and Dejonckere 2016);

and (2) classroom management: organization and discipline. Compared to normal speech, teaching represents a specific vocal demand (Hunter et al. 2020) and triggers the intentionality of the voice. Manfredi and Dejonckere (2016) defined the intentionality of the voice as "the need to 'operate' on the listener and to reach a goal.” As a vocal demand response (Hunter et al. 2020), teachers adapt their voice production, resulting in modifications of the acoustic voice signal in terms of frequency, intensity, and temporal aspects.

From the acoustic perspective, the teaching voice is characterized by an increase in fundamental frequency $\left(f_{\mathrm{o}}\right)$, intensity (Rantala et al. 2015; Remacle et al. 2014), and dynamic range (Manfredi and Dejonckere 2016), or intonation. The standard deviation of $f_{\mathrm{o}}\left(f_{\mathrm{o}} \mathrm{SD}\right)$ is an indicator of intonation: the greater the standard deviation, the more lively and interesting to listen to the voice is (Hincks 2004). Regarding the temporal aspects of speech, teaching involves turntaking: the teacher leaves silent pauses (i.e., interruption of the acoustic voice signal) to let the pupils express themselves. By helping to structure and highlight certain parts of a discourse, pauses help listeners to better integrate the message (Béchet et al. 2013). For the speaker, pauses make it possible to plan what will be said: the more cognitively demanding a task is, the higher the rate and duration of pauses (Kreiman and Sidtis 2011).

In addition, a teacher's voice is subject to constraints related to the audience (e.g., a group of pupils), the speaking mode (e.g., voice projection), and the environment, such as distance to the interlocutors and background noise impeding speech intelligibility (Schiller at al. In press). Background noise triggers automatic adaptation by the speaker, who involuntarily increases 
his/her vocal intensity and frequency to improve audibility: this is called the Lombard effect (Lombard 1911). To be more intelligible in background noise or when communicating with children, speakers decrease their speech rate and hyperarticulate, resulting in formant frequency changes (Smiljanic and Bradlow 2009). While $f_{\mathrm{o}}$ depends on the sound source (i.e., frequency of vocal fold oscillation), formant frequencies also depend on resonance of the supraglottal vocal tract and influence the sound spectrum (Titze et al. 2015). Regarding voice production, increased intensity and $f_{\mathrm{o}}$ are associated with a greater vocal load (Rantala et al. 2015; Remacle et al. 2014; Schiller et al. 2018) and vocal effort (Phadke et al. 2019), which can lead to phonotrauma and pathologies such as vocal fold nodules and polyps (Manfredi and Dejonckere 2016). At some point in their career, more than half of all teachers experience a voice disorder (Van Houtte et al. 2011). Because vocal behavior plays an important role in the pathogenesis of such disorders (Manfredi and Dejonckere 2016), the mastery of appropriate vocal skills is key to teachers' health, and their educational effectiveness.

Although they can improve a teacher's voice, prevention and treatment programs do not include the training of vocal skills in everyday teaching situations (Faham et al. 2016; Hazlett et al. 2011; López et al. 2017; Nanjundeswaran et al. 2012; Pizolato et al. 2013; Richter et al. 2016; Timmermans et al. 2012). In a clinical setting, it is difficult to practice vocal techniques for handling constraints such as speaking to a group of children against background noise. Consequently, it is challenging to generalize efficient speech patterns from the clinic to educational situations involving realistic constraints and maintain them there.

In the field of speech and language pathology, research examining virtual reality (VR) to enable improved communication for people with communication disabilities is limited (Bryant et al. 2019). The need to develop VR environments to provide therapeutic activities has been emphasized (Theodoros 2008). Their value is in simulating real-world, everyday communicative 
situations to allow specific competences to be practiced, by sparking the patient's motivation. Research has provided preliminary support for the idea that VR may be an effective tool in communication interventions (Bryant et al. 2019) for individuals with autism (Halabi et al. 2017), aphasia (Marshall et al. 2016), and stuttering (Brundage and Hancock, 2015). To date, the applicability of VR for voice training and rehabilitation has not yet been studied.

This study fits into the general approach that considers VR to be a tool for training teachers' vocal skills by simulating a communicative situation (a lesson) in a realistic environment (a classroom), characterized by environmental constraints that are often encountered (background noise, fidgety children). To evaluate the ecological validity of a virtual classroom in terms of vocal behavior in a teaching situation, we studied a group of teachers in three conditions: (1) speaking in a control condition, (2) teaching in their usual classroom (in vivo), and (3) teaching the same lesson in a virtual classroom (in virtuo).

Compared to normal speech, the response to teaching vocal demand should trigger the acoustic indices of Lombard speech, vocal intentionality (Manfredi and Dejonckere 2016) and effort. Thus, in the in vivo and in virtuo conditions, voices would be expected to have a higher $f_{\mathrm{o}}$ $(\mathrm{H} 1)$, greater intensity $(\mathrm{H} 2)$, and more intonation contrasts, measured via $f_{\mathrm{o}} \mathrm{SD}(\mathrm{H} 3)$. Teaching involves adaptation of the temporal aspects of speech to promote understanding of the message and interactions with pupils. We would therefore expect more frequent (H4) and longer (H5) pauses in the two classroom conditions than in the control condition.

We will also descriptively document the extent to which the virtual classroom creates a feeling of presence and does not generate unwanted negative side effects (commonly referred to as cybersickness). Finally, the link between measures related to VR exposure and vocal adaptation in the virtual classroom will be examined. 
Teachers' speech in a virtual classroom

\section{Methods}

This study was conducted in the Department of Speech Therapy of the University of Liège (Belgium). The Ethics Committee of the Faculty of Psychology, Speech Therapy, and Education Sciences approved it. All participants provided written informed consent after receiving a complete description of the study. During the recruitment procedure, they completed the sociodemographic and baseline questionnaires.

\subsection{Participants}

The sample included 30 female elementary school teachers aged 22 to 55 years old $(\mathrm{M}=$ 50; $\mathrm{SD}=10)$. Their teaching experience ranged between 1 and 35 years $(M=14 ; S D=9)$. Inclusion criteria: be a native French speaker; teach grade 4, 5 or 6 (pupils aged 9 to 12 years old) in a school in the French community in Belgium; be a woman. Exclusion criteria: report a voice or hearing disorder at the time of the study; report a strong tendency to motion sickness.

\subsection{Procedure}

The experiment took place on two consecutive days. On the first day, the teacher gave a typical lesson of her choice to her pupils in her usual classroom (in vivo condition). The average background noise level was measured in $\mathrm{dB}(\mathrm{A})$ (LAeq) throughout the lesson, using a calibrated Rion NL-21 sound level meter (Japan), placed at the back of the classroom at the height of the teacher's head. The noise level (including both ambient noise and teacher's speech) measured in vivo ranged from 54.6 to $74.7 \mathrm{~dB}$ LAeq $(\mathrm{M}=63.5 ; \mathrm{SD}=4)$ across the 30 classrooms.

The next day at the same time, the teacher performed two tasks at the laboratory, in a quiet room (background noise level $=35 \mathrm{~dB}(\mathrm{~A})$ ), measuring $4 \times 4 \times 2.5 \mathrm{~m}$. The first task was a 5minute free speech as in Astolfi et al. (2015), which involved introducing herself and describing a normal day, while facing the experimenter from $2 \mathrm{~m}$ away (control condition). This condition 
corresponds to what is usually done by speech pathologists to conduct clinical work with their patients. Second, the participant repeated the same lesson as the previous day in a virtual classroom developed for this research project (in virtuo condition). The background noise in the virtual environment was adjusted for each teacher so it was similar to the level measured in vivo the previous day.

In all three conditions, the teacher's speech was recorded with a Marantz PMD661MKIII digital recorder (Cumberland, RI) and an AKG C520L head-worn microphone (Vienna, Austria) positioned $5 \mathrm{~cm}$ from the mouth. The audio signal was recorded in .wav format, with a sampling frequency of $44.1 \mathrm{kHz}$ and 16-bit resolution.

\subsection{Virtual environment and equipment}

A virtual classroom used in our research lab was adapted for the in virtuo condition. The user wore an Oculus Rift ${ }^{\mathrm{TM}}$ head-mounted display.

The environment was an elementary school classroom with 16 pupils aged 9 to 12 years old animated with typical childlike actions (Figure 1). The auditory stimuli were spatialized and played through the speakers of the head-mounted display; they corresponded to background noise without understandable semantic content, as described in Klatte et al. (2010) and Phadke et al. (2019). The experimenter can adjust the volume of three noise sources and the children's agitation level (Figure 2), which allows for clinical flexibility. Thus, it was possible to standardize our experiment based on the situation each teacher experienced in vivo. For each participant, the background noise generated in the headset speakers was calibrated so that it would be identical to the average noise level (LAeq) measured the previous day in vivo. The agitation level was always set at $30 \%$, corresponding to a slightly restless class. 
Before the immersive experience, each participant received the following instructions: "You are going to teach your lesson to a class of fourth/fifth/sixth graders [cf. the teacher's actual grade level]. This lesson will last $x$ minutes [same duration as in vivo]. Please try to give the same lesson as yesterday. The virtual environment doesn't allow for interaction: if you ask questions, the pupils won't answer you."

\subsection{Measures}

\subsubsection{Baseline descriptive measures}

In addition to sociodemographic information, the following questionnaires were completed.

Voice problems. The Voice Handicap Index (VHI) measures the biopsychosocial impact of voice problems (Jacobson et al. 1997; Woisard et al. 2004). This questionnaire comprises 30 self-rated items on a 5-point Likert scale $(0=$ never; $4=$ always $)$. The total score ranges from 0 (no complaints) to 120 (many complaints).

Immersive tendency. The Immersive Tendencies Questionnaire (ITQ) measures the tendencies of individuals to experience presence in common activities (Witmer and Singer 1998; Robillard et al. 2002). This scale contains 18 self-rated items on a 7-point Likert scale $(0=$ never; $6=$ often $)$

\subsubsection{Measures related to VR exposure}

Cybersickness. To control for potential unwanted negative side effects of VR exposure, each participant completed the Simulator Sickness Questionnaire (SSQ) (Bouchard et al. 2009; Kennedy et al. 1993) before and after the in virtuo condition. The SSQ rates 16 symptoms of simulator sickness on a 4-point Likert scale; the scoring is based on raw scores, as recommended by Bouchard et al. (2009). 
Presence. The feeling of presence in VR was measured using the Presence Questionnaire (PQ) (Robillard et al. 2002; Witmer and Singer 1998) completed after the in virtuo condition. Nineteen items are self-rated on a 7-point Likert scale, providing scores on six subscales.

\subsubsection{Voice measures}

As mentioned by Smiljanic and Bradlow (2009), there are two broad categories of measurements: (1) global ones including measures such as pause rate and duration, $f_{\mathrm{o}}$ and its variation; and (2) segmental measurements including vowel formant changes, vowel space, and segment duration. As this is the first study on the validity of a virtual classroom for investigating vocal behavior, we opted for global measurements.

For the control, in vivo and in virtuo recordings of spontaneous productions, acoustic analysis was conducted using Praat freeware (version 6.1.04). The following parameters were extracted from connected speech: median $f_{\mathrm{o}}$ (in $\mathrm{Hz}$ ) using an autocorrelation method, $f_{\mathrm{o}}$ variation through the standard deviation $\left(f_{\mathrm{o}} \mathrm{SD}\right)$, and mean voice intensity (in $\left.\mathrm{dB}\right)$. We computed the mean duration (ms) and rate (number per minute) of pauses, considering a minimum silent interval of $350 \mathrm{~ms}$. For each participant, the duration of recordings analyzed was similar for both the in vivo and in virtuo conditions ( $\mathrm{M}=15$ minutes; $\min -\max =6-24$ minutes $)$.

To determine vocal adaptation when teaching in the virtual classroom, we calculated the difference between each voice measure in virtuo and during free speech $(\Delta=$ in virtuo - Control).

\subsection{Statistical analysis}

To test the hypothesized difference between the teaching and control conditions, repeated measures ANOVAs were conducted with the three conditions as a within-subject factor. The Bonferroni correction was applied considering the five acoustic measures $(\alpha=0.05 / 5)$. When the $p$-value was lower than 0.01 , the null hypothesis of equal means was rejected and simple 
orthogonal contrast analyses were performed to test (1) the difference between the control and in vivo conditions, and (2) the difference between the control and in virtuo conditions. Our aim was to identify voice and speech adaptations in both real and virtual classrooms, the reference point being the free speech condition. The in vivo and in virtuo conditions were not compared directly for three reasons: (1) comparing all conditions would make the analysis non-orthogonal, thus impacting power and consistency with our research hypotheses; (2) this involves testing the null hypothesis that there is no difference between in vivo and in virtuo conditions, thus raising the issue of inadequate sample size and power for that specific contrast; and (3) we have no empirical basis to justify a hypothesis that there is, or is not, a difference between in vivo and in virtuo conditions. Effect sizes are reported using partial $\eta^{2}$.

The applicability of the analyses was checked in advance, particularly normality using the Shapiro-Wilk test and the assumption of homogeneous variances using Mauchly's sphericity test. When the sphericity hypothesis was violated, the Greenhouse-Geisser correction adjusting the degrees of freedom is reported. All analyses were performed using SPSS, version 25.

\section{Results}

\subsection{Descriptive results}

Regarding baseline descriptive results, the VHI score $(\mathrm{M}=13.83$; SD $=13.55)$ was slightly higher than the normative data for a population without voice disorders $(\mathrm{M}=6.57 ; \mathrm{SD}=$ 5.16) reported by Woisard et al. (2004). According to these normative data, four teachers exceeded the maximum cut-off score for normality $(=20)$ but did not differ from the other participants in their acoustic measures.

Table 1 shows that the participants were not very familiar with VR and video games: $66.7 \%$ of them had never tried a VR helmet or glasses, and $73.3 \%$ never played video games. 
As for VR exposure results, Table 2 reports on the immersive tendency, feeling of presence experienced and unwanted side effects. Qualitatively, the mean ITQ score was within the normal range (Robillard et al. 2002), which means that our participants tended to experience immersion comparable to that of the general population. The PQ scores were within the normal range (Robillard et al. 2002), except for the interface quality subscale: several participants reported that the image was pixelated. Paired $t$-tests did not show a significant difference in SSQ scores before and after the in virtuo condition $(t=.897, p=.377)$.

We investigated the potential relationships between sociodemographic variables and voice acoustic measures. In particular, we calculated Pearson correlations between age, teaching experience and each acoustic measure for the control, in vivo, and in virtuo conditions. As no significant correlation was found, we do not describe these results at length but will focus on the validation of the virtual classroom in terms of vocal behavior.

\subsection{Voice outcome measures}

Table 3 presents the within-subject effect of repeated measures ANOVAs and Figure 3 presents the mean values and SD of the acoustic measures.

Regarding voice frequency, there was a significant effect of condition. The contrast analyses showed higher $f_{\mathrm{o}}$ values in vivo $\left(F(1)=282.17, p<.001, \eta^{2}=.907\right)$ and also in virtuo $\left(F(1)=202.74, p<.001, \eta^{2}=.875\right)$ compared to the free speech control condition produced in the lab. All participants showed a similar adaptation when teaching, consisting in a global $f_{\mathrm{o}}$ rise over the entire lesson in vivo and in virtuo.

We found a significant effect of condition on voice intensity. Compared to the control condition, contrast analyses indicated that teachers spoke louder in vivo $(F(1)=104.08, p<.001$, $\left.\eta^{2}=.782\right)$ and in virtuo $\left(F(1)=168.48, p<.001, \eta^{2}=.853\right)$. All participants adjusted to the 
teaching situations by systematically raising their voices, except one who had a similar intensity in the control and in vivo conditions.

Similarly, we found a significant effect of condition on intonation. Compared to free speech, contrast analyses showed greater $f_{\mathrm{o}}$ variations of voice in vivo $(F(1)=218.76, p<.001$, $\left.\eta^{2}=.883\right)$ and in virtuo $\left(F(1)=158.29, p<.001, \eta^{2}=.845\right)$. All participants increased their intonation contrasts when teaching in their real classroom. The same adaptation was found in virtuo, except for one teacher who used less intonation when teaching in the virtual classroom than during free speech.

There was no significant effect of condition on the pause rate, meaning that the teachers did not pause more often when teaching compared to the free speech condition. Intersubject variability was observed: 20 participants systematically paused more frequently when teaching (both in vivo and in virtuo) than during free speech; 4 participants systematically paused less frequently when teaching (both in vivo and in virtuo) than during free speech. We also note intrasubject variability of the pause rate: 5 teachers adopted different adaptations across the two teaching conditions.

Finally, we found a significant effect of condition on the duration of pauses. All speakers made longer pauses while teaching in vivo $\left(F(1)=106.05, p<.001, \eta^{2}=.785\right)$ than during free speech. When teaching in the virtual classroom, 23 out of 30 teachers made longer pauses compared to the free speech condition $\left(F(1)=4.25, p=.048, \eta^{2}=.128\right)$.

Table 4 presents the relationships between vocal adaptations in the virtual classroom and the global scores on the questionnaires. None of the Pearson correlations was statistically significant, meaning that the vocal changes observed in the virtual classroom are not related to immersive tendencies, the feeling of presence, cybersickness symptoms, or reported voice problems. 
Teachers' speech in a virtual classroom

\section{Discussion}

This study aimed to validate the use of a virtual classroom in terms of adaptation of teachers' speech characteristics in a teaching situation (a lesson) in a realistic environment (a classroom), featuring environmental constraints (background noise, restless pupils), comparing three conditions: (1) free speech produced in a control condition, (2) teaching in vivo, and (3) teaching in virtuo. We wanted to find out whether, compared to the control condition, teaching triggered specific acoustic changes, both in vivo and in a virtual classroom. From a methodological perspective, teachers were instructed to give the same lesson in vivo and in virtuo. The time between the conditions was strictly controlled (1 day). The intensity of background noise was individually controlled for each participant and was similar in both teaching conditions.

The results correspond to acoustic measures of the speech signal in the three conditions. Global measures were calculated on each entire recording of spontaneous speech, and may be complemented by segmental measures to identify some temporal and local variations. In line with $\mathrm{H} 1$, compared to speech during the control situation, which represented what is traditionally done in a clinic, the $f_{\mathrm{o}}$ was significantly higher in a teaching situation, both in vivo $(+68 \mathrm{~Hz}$ or 5.5 semitones on average) and in virtuo (+41 Hz or 3.5 semitones). Similarly, teachers spoke significantly louder when teaching in vivo $(+6.1 \mathrm{~dB})$ and in virtuo $(+6.3 \mathrm{~dB})$, compared to the control situation, which supports $\mathrm{H} 2$. As depicted in Figure 3b, the difference between the in vivo and in virtuo teaching conditions was clinically negligible $(+1 \mathrm{~dB})$. These results suggest that the nature of the $f_{\mathrm{o}}$ and intensity adaptations was similar in both teaching situations, but the amplitude of the changes is less pronounced when teaching in the virtual classroom.

Previous studies measured higher voice $f_{\mathrm{o}}$ and intensity in teachers speaking in their professional environment compared to extra-professional situations (Remacle et al. 2014; Schiller 
et al. 2018). Increased $f_{\mathrm{o}}$ and intensity in the teaching conditions may be triggered by background noise (Rantala et al. 2015; Schiller et al. 2018). Lombard speech has previously been described in noisy environments such as schools (Rantala et al. 2015). This kind of automatic adaptation is likely to provoke increased vocal effort (Phadke et al. 2019) and vocal load (Rantala et al. 2015; Schiller et al. 2018). Professional voice users such as teachers need excellent vocal skills so they can make themselves understood in noisy environments without adopting phonotraumatic behavior. The results of this study show that the virtual classroom seems to allow teachers to practice these skills, as teachers produce specific vocal demand responses (Hunter et al. 2020) even when the stimuli are virtual.

In line with $\mathrm{H} 3$, significantly more intonation contrast ( $f_{\mathrm{o}}$ variation) was produced when teaching in vivo $(+25 \mathrm{~Hz})$ and in virtuo $(+17 \mathrm{~Hz})$ than in the control situation. From a qualitative point of view, the participants adopted similar intonation adaptations when teaching, with a less pronounced change in the virtual classroom. This prosodic feature may help teachers to make their speech pleasant and interesting to listen to (Hincks, 2004), to keep the pupils' attention and fulfill pedagogic goals. In addition, the characteristics of child-directed speech may have applied in the teaching conditions: adults spontaneously adopt higher $f_{\mathrm{o}}$ and greater $f_{\mathrm{o}}$ variability when speaking to children (Saint-Georges et al. 2013).

Contrary to $\mathrm{H} 4$, statistical analysis did not indicate that teachers pause more often during lessons, either in vivo or in virtuo. This measure showed particularly large intersubject variability. But in accordance with $\mathrm{H} 5$, the duration of pauses was significantly longer when teaching in vivo (+928 ms) and in virtuo (+176 ms), compared to the control condition. Longer pauses during teaching may allow turn-taking, which was difficult to simulate in virtuo given that the environment did not provide for any audience reaction to the user's speech. In the presence of 
background noise, longer pauses may also reflect a slower speech rate with the aim of improving intelligibility (Astolfi et al. 2015).

To sum up, the changes in acoustic parameters were statistically significant, with large effect sizes. Qualitatively speaking, the magnitude of differences compared to the control condition was smaller in virtuo than in vivo. However, the acoustic changes in the VR condition systematically reflected the same kinds of speech adaptation as in a real classroom. In a clinical setting, adjusting the noise level and pupil agitation level in the virtual classroom could make it possible to gradually increase the difficulty of the task and to elicit speech adaptations of similar amplitude to real teaching situations.

In addition to the acoustic measures presented above, the experimenter reported the following subjective observations: while teaching in virtuo, the participants projected their voices, looked at the pupils, moved around the virtual environment, and gestured with their arms to punctuate their speech. For a more general description of communication in VR environments, it would be interesting to use sensors to capture variables related to posture, gestures and eye movements.

Finally, some technical limitations may have affected the VR experience. The first was the lack of interaction with the audience: the virtual characters did not answer questions and did not react to the teacher's speech. This could have reduced the feeling of co-presence and social presence, although these factors were not measured in this study. Future VR classrooms could benefit from implementing real-time audience feedback, as in VR applications used to train presenters' skills (El-Yamri et al. 2019; Schneider et al. 2019). Second, teachers reported missing the possibility of using written material (e.g., notes on a sheet or a screen), and of writing on a blackboard. These suggestions represent possible future improvements that could enhance the user experience and the effectiveness of the virtual environment. 


\section{Conclusions}

Learning communication skills such as effective voice use while teaching requires practice in situations that are as similar as possible to reality. VR simulations may represent a promising method to offer several applications for voice training for future teachers (instruction) and rehabilitation for dysphonic individuals (speech and language pathology). In this respect, our study validated the effects of a virtual classroom on the acoustic characteristics of teachers' speech during a lesson. The results suggest that the virtual classroom elicited changes in voice frequency and intensity, and in speech intonation contrasts and pauses, compared to a control speaking situation. The strong feeling of presence and the lack of side effects such as cybersickness may promote the generalization of communication skills practiced in the virtual classroom to real-world situations. The next step is to conduct randomized controlled trials to assess the efficacy of VR for vocal skill training and rehabilitation.

\section{Acknowledgments}

Angélique Remacle was supported by the Fund for Scientific Research - FNRS (F.R.S.-

FNRS, Brussels, Belgium). This work was supported by a Canada Research Chairs grant awarded to Stéphane Bouchard and a grant from the Commission Mixte Permanente Québec/WallonieBruxelles awarded to Stéphane Bouchard and Anne-Marie Etienne. We thank Amandine Regnier for her assistance with data collection; Sysmex Belgium N.V. for providing the NL-21 sound level meter used in the study; and Jean-Jacques Embrechts, of the Montefiore Institute at the University of Liège, for his assistance with the calibration of the noise level in the VR environment. 


\section{Author Disclosure Statement}

Stéphane Bouchard is president and part owner of In Virtuo, a company that distributes virtual environments. Conflicts of interest are managed under UQO's conflicts of interest policy. For all the other authors, no competing financial interests exist.

\section{References}

Astolfi A, Carullo A, Pavese L, Puglisi GE (2015) Duration of voicing and silence periods of continuous speech in different acoustic environments. J Acoustical Soc Am 137:565-579.

\section{https://doi.org/10.1121/1.4906259}

Béchet M, Sandré M, Hirsch F, Richard A, Marsac F, Sock R (2013) Uses of the silent pause in political debates on TV. A case study of François Hollande. Mots. Les langages du politique 103:23-38. https://doi.org/10.4000/mots.21460

Bouchard S, St-Jacques J, Renaud P, Wiederhold BK (2009) Side effects of immersions in virtual reality for people suffering from anxiety disorders. J Cyber Rehabil 2:127-137.

Brundage S, Hancock A (2015) Real enough: Using virtual public speaking environments to evoke feelings and behaviors targeted in stuttering assessment and treatment. Am J Speech Lang Pathol 24:139-149. https://doi.org/10.1044/2014_AJSLP-14-0087

Bryant L, Brunner M, Hemsley B (2019) A review of virtual reality technologies in the field of communication disability: Implications for practice and research. Disabil Rehabil Assist Technol 13:1-8. https://doi.org/10.1080/17483107.2018.1549276 
Teachers' speech in a virtual classroom

El-Yamri M, Romero-Hernandez A, Gonzalez-Riojo M, Manero B (2019) Emotions-responsive audiences for VR public speaking simulators based on the speakers' voice. In: IEEE 19th International Conference on Advanced Learning Technologies (ICALT). Maceió, pp 349-353

Faham M, Ahmadi A, Drinnan M, Saadatmand N, Fatahi E, Jalalipour M (2016) The effects of a voice education program on VHI scores of elementary school teachers. J Voice 30:755.e1755.e11. https://doi.org/10.1016/j.jvoice.2015.09.009

Halabi O, El-Seoud SA, Alja'am JM, Alpona H, Al-Hemadi M, Al-Hassan D (2017) Design of immersive virtual reality system to improve communication skills in individuals with autism. Int J Emerg Technol Learning 12:50-64. https://doi.org/10.3991/ijet.v12i05.6766

Hazlett DE, Duffy OM, Moorhead SA (2011) Review of the impact of voice training on the vocal quality of professional voice users: Implications for vocal health and recommendations for further research. J Voice 25:181-191. https://doi.org/10.1016/j.jvoice.2009.08.005

Hincks R (2004) Standard deviation of F0 in student monologue. In: Branderud P, Traunmüller H (eds) Proceedings of Fonetik 2004. Institutionen för lingvistik, Stockholm, pp 132-135

Hunter EJ, Cantor-Cutiva LC, van Leer E et al (2020) Toward a consensus description of vocal effort, vocal load, vocal loading, and vocal fatigue. J Speech Lang Hear Res 63:509-532. https://doi.org/10.1044/2019 JSLHR-19-00057 
Jacobson BH, Johnson A, Grywalski C, et al (1997) The voice handicap index (VHI):

Development and validation. Am J Speech Lang Pathol 6:66-70. https://doi.org/10.1044/1058$\underline{0360.0603 .66}$

Kennedy RS, Lane NE, Berbaum KS, Lilienthal, MG (1993) Simulator sickness questionnaire: An enhanced method for quantifying simulator sickness. Int J Aviat Psychol 3:203-220. https://doi.org/10.1207/s15327108ijap0303_3

Klatte M, Lachmann T, Meis M (2010) Effects of noise and reverberation on speech perception and listening comprehension of children and adults in a classroom-like setting. Noise Health 12:270-282. https://doi.org/10.4103/1463-1741.70506

Kreiman J, Sidtis D (2011) Foundations of voice studies: An interdisciplinary approach to voice production and perception. Wiley-Blackwell, Malden.

Lombard E (1911) Le signe de l'élévation de la voix. Ann Mal Oreil Larynx 37:101-119

López JM, Catena A, Montes A, Castillo ME (2017) Effectiveness of a short voice training program for teachers: A preliminary study. J Voice 31:697-706.

https://doi.org/10.1016/j.jvoice.2017.01.017

Manfredi C, Dejonckere PH (2016) Voice dosimetry and monitoring, with emphasis on professional voice diseases: Critical review and framework for future research. Logop Phoniatr Vocol 41:49-65. https://doi.org/10.3109/14015439.2014.970228 
Teachers' speech in a virtual classroom

Marshall J, Booth T, Devane N, et al (2016) Evaluating the benefits of aphasia intervention delivered in virtual reality: Results of a quasi-randomised study. PLoS ONE 11:e0160381. https://doi.org/10.1371/journal.pone.0160381

Nanjundeswaran C, Li NY, Chan KM, Wong RK, Yiu EML, Verdolini-Abbott K (2012)

Preliminary data on prevention and treatment of voice problems in student teachers. J Voice 26:816.e1-816.e12. https://doi.org/10.1016/j.jvoice.2012.04.008

Phadke KV, Abo-Hasseba A, Švec JG, Geneid A (2019) Influence of noise resulting from the location and conditions of classrooms and schools in Upper Egypt on teachers' voices. J Voice 33:802.e1-802.e9. https://doi.org/10.1016/j.jvoice.2018.03.003

Pizolato RA, Rehder MIBC, dos Santos Dias CT et al (2013) Evaluation of the effectiveness of a voice training program for teachers. J Voice 27:603-610.

https://doi.org/10.1016/j.jvoice.2013.04.013

Rantala LM, Hakala S, Holmqvist S, Sala E (2015) Classroom noise and teachers' voice production. J Speech Lang Hear Res 58:1397-1406. https://doi.org/10.1044/2015_JSLHR-S-14$\underline{0248}$

Remacle A, Morsomme D, Finck C (2014) Comparison of vocal loading parameters in kindergarten and elementary school teachers. J Speech Lang Hear Res 57:406-415. https://doi.org/10.1044/2013 JSLHR-S-12-0351 
Teachers' speech in a virtual classroom

Richter B, Nusseck M, Spahn C, Echternach M (2016) Effectiveness of a voice training program for student teachers on vocal health. J Voice 30:452-459.

https://doi.org/10.1016/j.jvoice.2015.05.005

Robillard G, Bouchard S, Renaud P, Cournoyer LG (2002) Validation canadienne-française de deux mesures importantes en réalité virtuelle: l’Immersive Tendencies Questionnaire et le Presence Questionnaire. Poster presented at the 25th conference of the Société Québécoise pour la Recherche en Psychologie (SQRP), Trois-Rivières, QC, November 1-3.

Saint-Georges C, Chetouani M, Cassel R et al (2013) Motherese in interaction: At the cross-road of emotion and cognition? (A systematic review). PLoS ONE 8:e78103.

https://doi.org/10.1371/journal.pone.0078103

Schiller I, Morsomme D, Kob M, Remacle A (in press) Noise and a speaker's impaired voice quality disrupt spoken language processing in school-aged children: Evidence from performance and response time measures. J Speech Lang Hear Res. https://doi.org/10.1044/2020_JSLHR-19$\underline{00348}$

Schiller I, Morsomme D, Remacle A (2018) Voice use among music theory teachers: A voice dosimetry and self-assessment study. J Voice 32:578-584.

https://doi.org/10.1016/j.jvoice.2017.06.020 
Teachers' speech in a virtual classroom

Schneider J, Romano G, Drachsler H (2019) Beyond reality - Extending a presentation trainer with an immersive VR module. Sensors 19:3457. https://doi.org/10.3390/s19163457

Smiljanic R, Bradlow A (2009) Speaking and hearing clearly: Talker and listener factors in speaking style changes. Lang Linguist Compass 3:236-264. https://doi.org/10.1111/j.1749818X.2008.00112.x

Theodoros DG (2008) Telerehabilitation for service delivery in speech-language pathology. $\mathbf{J}$ Telemed Telecare 14:221-224. https://doi.org/10.1258/jtt.2007.007044

Timmermans B, Coveliers Y, Wuyts FL, Van Looy L (2012) Voice training in teacher education: The effect of adding an individualized microteaching session of 30 minutes to the regular 6-hour voice training program. J Voice 26:669.e1-669.e9. https://doi.org/10.1016/j.jvoice.2011.03.001

Titze I, Baken RJ, Bozeman KW et al (2015) Toward a consensus on symbolic notation of harmonics, resonances, and formants in vocalization. J Acoust Soc Am 137:3005. https://asa.scitation.org/doi/10.1121/1.4919349

Van Houtte E, Claeys S, Wuyts F, Van Lierde K (2011) The impact of voice disorders among teachers: Vocal complaints, treatment-seeking behavior, knowledge of vocal care, and voicerelated absenteeism. J Voice 25:570-575. https://doi.org/10.1016/j.jvoice.2010.04.008

Witmer BG, Singer MJ (1998) Measuring presence in virtual environments: A presence questionnaire. Presence (Camb) 7:225-240. https://doi.org/10.1162/105474698565686 
Teachers' speech in a virtual classroom

Woisard V, Bodin S, Puech M (2004) [The Voice Handicap Index: Impact of the translation in French on the validation]. Rev Laryngol Otol Rhinol (Bord) 125:307-312. 
Figure 1 Virtual environment used for the in virtuo condition

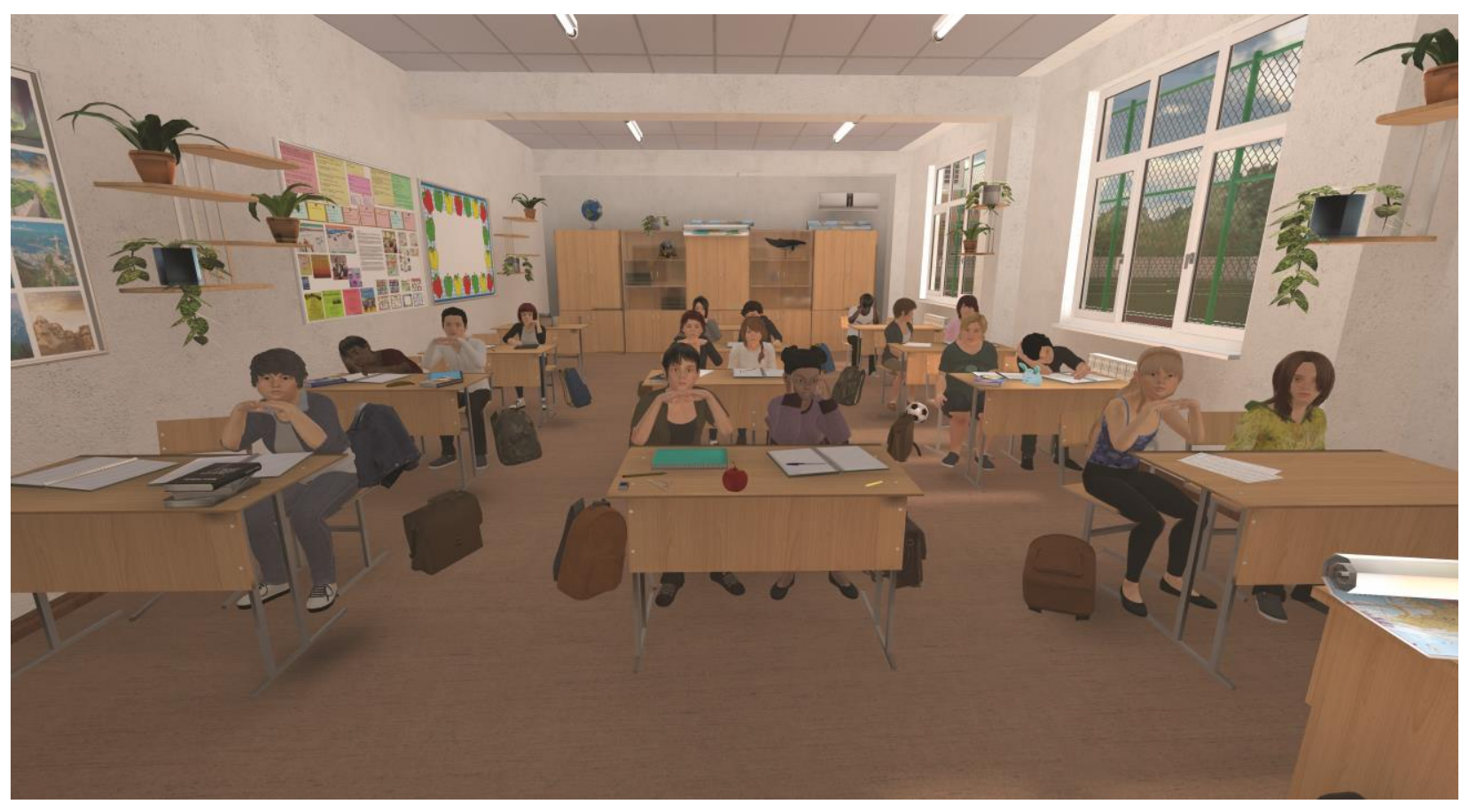


Figure 2 Control panel for the parameters of the virtual environment. Above: individual adjustment of three sources of background noise: (1) noise from the playground, (2) noise from the corridor, and (3) noise from inside the classroom. Below: adjustment of the pupils' agitation level from 0 (very attentive and not very restless) to 100 (very distracted and restless). For this study, all three noise sources were adjusted to the same level. For each participant, the noise level played through the head-mounted speakers was identical to the average noise level in the in vivo condition. The agitation level was set to 30 for all participants

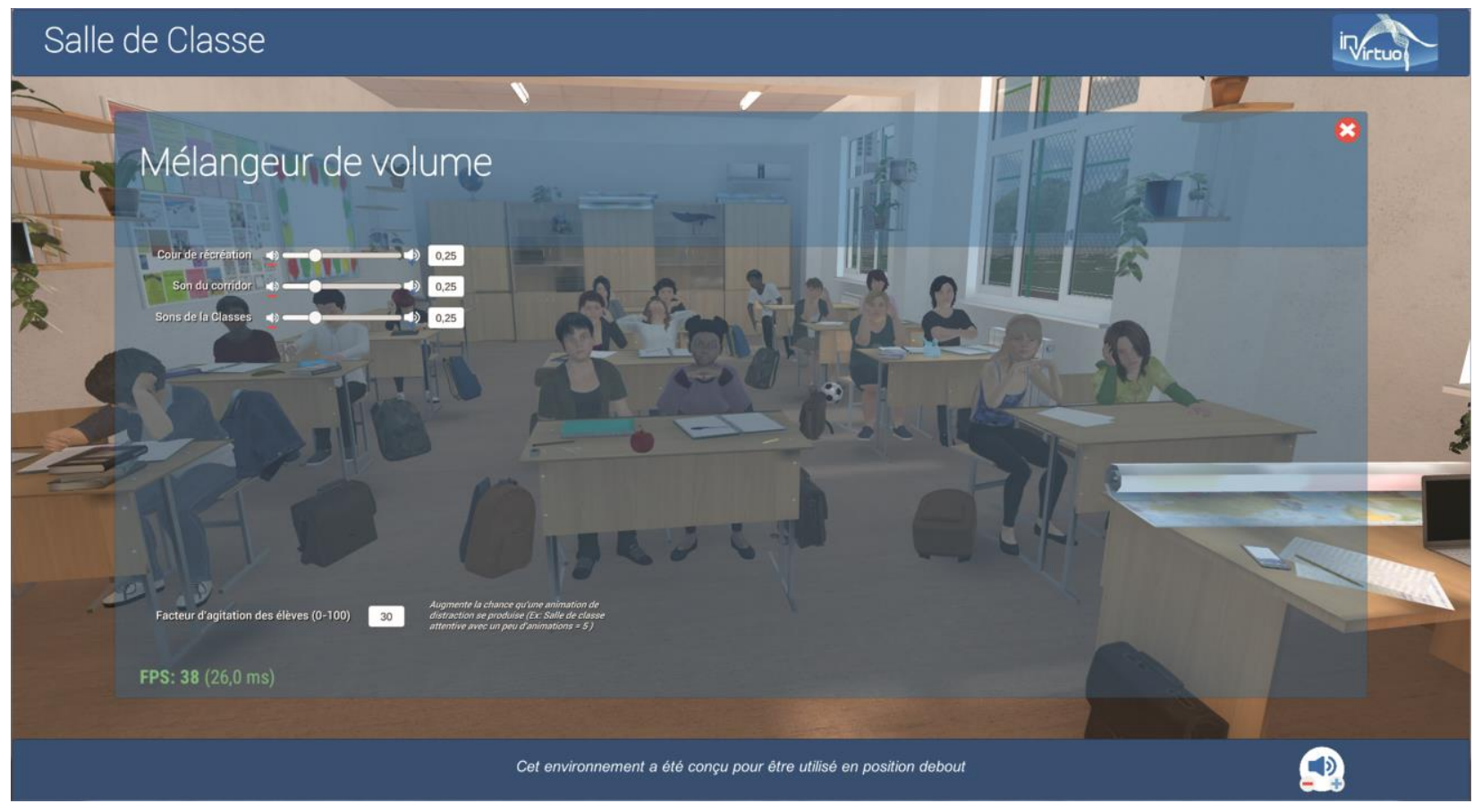

Figure 3 Descriptive results of vocal parameters of teachers giving a free speech in the lab (control), a lesson in their real-world classroom (in vivo) and the same lesson while immersed in VR (in virtuo), with background noise matched to the level in their in vivo classroom. Mean values are reported in the bars, while error bars represent $\pm 1 \mathrm{SD}$ 
a.

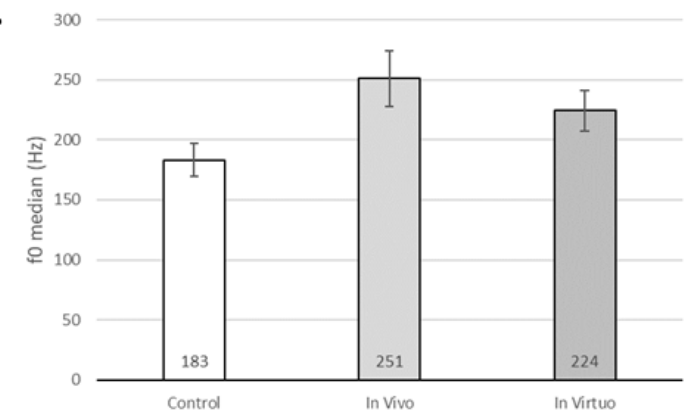

b.

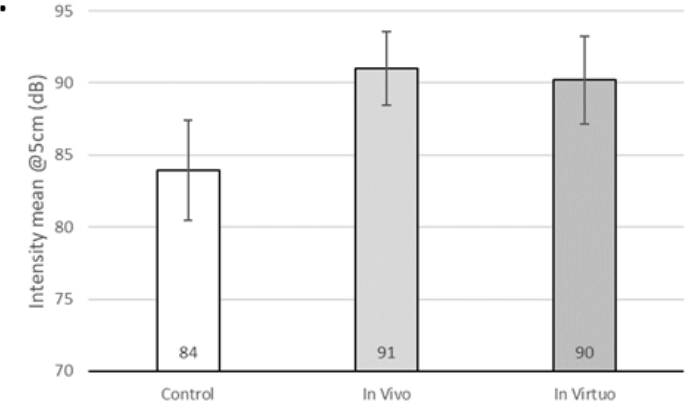

c.

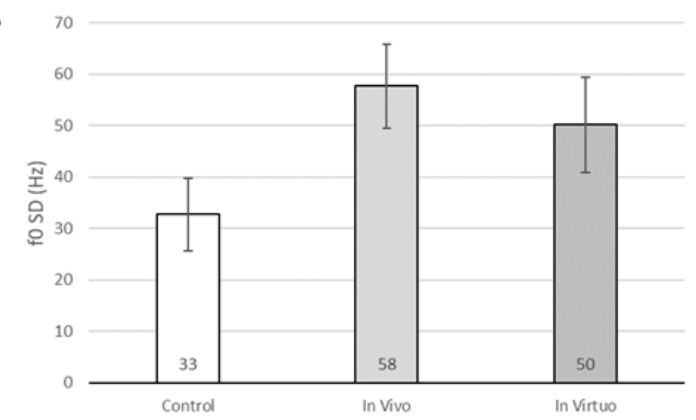

d.

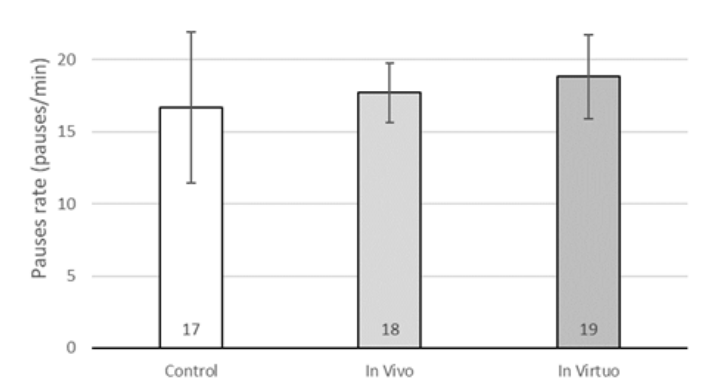

e.

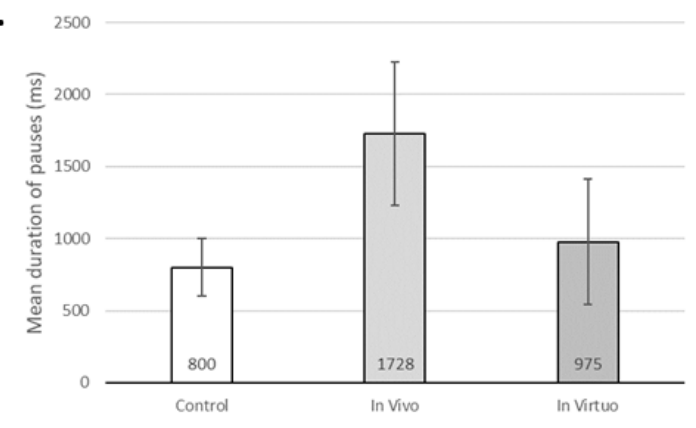

This is a post-peer-review, pre-copyedit version of an article published in Virtual Reality. The final authenticated version is available online at: http://dx.doi.org/10.1007/s10055-020-00491-1 
Table 1. Description of the sample of 30 female teachers enrolled in the study

\begin{tabular}{llc}
\hline Socio-professional variables & $\mathrm{n}$ & $\%$ \\
\hline Teaching level & & \\
Grade 4 & 10 & 33.3 \\
Grade 5 & 9 & 30 \\
Grade 6 & 6 & 20 \\
Grades 5 and 6 & 3 & 10 \\
Grades 4, 5, and 6 & 2 & 6.7 \\
Work schedule & & \\
Full-time & 23 & 76.7 \\
Part-time & 7 & 23.3 \\
\hline Voice variables & \multicolumn{2}{c}{} \\
\hline Leisure involving voice use & 2 & 6.7 \\
Theater & 1 & 3.3 \\
Singing in a choir & 2 & 6.7 \\
Team sport & 25 & 83.3 \\
None & 6 & 20 \\
Had received voice education during studies or career & 4 & 13.3 \\
Had consulted a medical doctor or a speech therapist for a voice problem & 10 & 33.3 \\
Had consulted a medical doctor for a gastro-esophageal problem & 5 & 16.7 \\
Smoking
\end{tabular}

\section{Digital and virtual reality habits}

How often do you play games on your smart phone?

Every day

Several times a week

$0 \quad 0$

Several times a month

$5 \quad 16.7$

Less often

$3 \quad 10$

I don't have a smart phone

$16 \quad 53.3$

$1 \quad 3.3$

How often do you play video games?

\section{Every day}

Several times a week

Several times a month

Less often

Never

0

$0 \quad 0$

$3 \quad 10$

$5 \quad 16.7$

$22 \quad 73.3$

How comfortable do you feel with digital technologies?

1 (not at all comfortable)

$\begin{array}{ll}1 & 3.3 \\ 1 & 3.3 \\ 0 & 0 \\ 8 & 26.7 \\ 13 & 43.3 \\ 7 & 23.3 \\ 0 & 0\end{array}$

Have you ever tried a virtual reality helmet or glasses?

Never

$20 \quad 66.7$

Less than 3 times

930

From 3 to 5 times 
Teachers' speech in a virtual classroom 
Table 2. Descriptive results for VR-related variables associated with teaching a lesson while immersed in a virtual classroom

\begin{tabular}{ll}
\hline Questionnaires & Mean score (SD) \\
\hline Immersive Tendencies Questionnaire (ITQ) $^{\mathrm{a}}$ & $62.23(14.45)$ \\
Simulator Sickness Questionnaire (SSQ) & \\
Before teaching in virtuo & $5.50(4.87)$ \\
After teaching in virtuo & $4.97(4.54)$ \\
Presence Questionnaire (PQ) & \\
Realism & $29.6(8.60)$ \\
Affordance to act & $15.17(5.04)$ \\
Interface quality & $8.40(3.56)$ \\
Affordance to examine & $14.13(3.13)$ \\
$\quad$ Self-evaluation of performance & $8.13(1.59)$ \\
$\quad$ Auditory & $16.03(4.09)$ \\
\hline a. & Administered before the experiment \\
b. Administered after the in virtuo condition
\end{tabular}


Table 3. Repeated measures ANOVAs comparing vocal parameters of teachers giving a free speech in the lab (control), a lesson in their real-world classroom (in vivo) and the same lesson while immersed in VR (in virtuo), with background noise matched to the level in the in vivo classroom

\begin{tabular}{lllll}
\hline & $\mathrm{df}$ & $\mathrm{F}$ & $\mathrm{p}$ & $\eta^{2}$ \\
\hline$f_{\mathrm{o}}$ median & 2,58 & 182.02 & $<.001$ & .863 \\
Intensity mean $^{\mathrm{a}}$ & $1.59,45.99$ & 94.26 & $<.001$ & .765 \\
Intonation $\left.^{\mathrm{f}} f_{\mathrm{o}} \mathrm{SD}\right)$ & 2,58 & 142.36 & $<.001$ & .831 \\
Pause rate $^{\mathrm{a}}$ & $1.53,44.53$ & 3.31 & .058 & .102 \\
Mean duration of pauses $^{2}$ & 2,58 & 56.51 & $<.001$ & .661 \\
\hline
\end{tabular}

${ }^{\mathrm{a}}$ Greenhouse-Geisser correction reported 
Table 4. Correlations between vocal adaptations in the VR classroom (in virtuo) and global scores on the questionnaires. For each voice measure, the adaptation when teaching in the VR classroom was obtained by calculating the difference between the in virtuo and control conditions $(\Delta=$ in virtuo - Control)

\begin{tabular}{|c|c|c|c|c|}
\hline & $\begin{array}{l}\text { Voice Handicap } \\
\text { Index }(\mathrm{VHI})^{\mathrm{a}}\end{array}$ & $\begin{array}{l}\text { Immersive } \\
\text { Tendencies } \\
\text { Questionnaire (ITQ) }\end{array}$ & $\begin{array}{l}\text { Simulator Sickness } \\
\text { Questionnaire } \\
(\mathrm{SSQ})^{\mathrm{b}}\end{array}$ & $\begin{array}{l}\text { Presence } \\
\text { Questionnaire } \\
(\mathrm{PQ})^{\mathrm{b}}\end{array}$ \\
\hline$\Delta f_{\mathrm{o}}$ median & $\mathrm{r}=-.056, \mathrm{p}=.77$ & $\mathrm{r}=-.022, \mathrm{p}=.91$ & $\mathrm{r}=.197, \mathrm{p}=.30$ & $\mathrm{r}=-.008, \mathrm{p}=$ \\
\hline$\Delta$ Intensity mean & $\mathrm{r}=-.132, \mathrm{p}=.49$ & $r=-.165, p=.38$ & $\mathrm{r}=-.055, \mathrm{p}=.77$ & $\mathrm{r}=-.136, \mathrm{p}=$ \\
\hline$\Delta$ Intonation $\left(f_{\mathrm{o}} \mathrm{SD}\right)$ & $\mathrm{r}=-.129, \mathrm{p}=.49$ & $\mathrm{r}=-.108, \mathrm{p}=.57$ & $\mathrm{r}=.230, \mathrm{p}=.22$ & $\mathrm{r}=-.165, \mathrm{p}=.3$ \\
\hline$\Delta$ Pause rate & $\mathrm{r}=-.337, \mathrm{p}=.07$ & $\mathrm{r}=-.298, \mathrm{p}=.11$ & $\mathrm{r}=-.075, \mathrm{p}=.69$ & $\mathrm{r}=.111, \mathrm{p}=.56$ \\
\hline$\Delta$ Mean duration of pauses & $r=.154, p=.42$ & $\mathrm{r}=-.014, \mathrm{p}=.94$ & $r=.263, p=.16$ & $\mathrm{r}=-.264, \mathrm{p}=$ \\
\hline
\end{tabular}

